\title{
eRPL : An Enhanced RPL Based Light-Weight Routing Protocol in a IoT Capable Infra-Less Wireless Networks
}

\author{
Hayoung $\mathrm{Oh}^{\dagger}$
}

\begin{abstract}
The first mission for the IoT based hyper-connectivity communication is developing a device-to-device communication technique in infra-less low-power and lossy networks. In a low-power and lossy wireless network, IoT devices and routers cannot keep the original path toward the destination since they have the limited memory. Different from the previous light-weight routing protocols focusing on the reduction of the control messages, the proposed scheme provides the light-weight IPv6 address auto-configuration, IPv6 neighbor discovery and routing protocol in a IoT capable infra-less wireless networks with the bloom filer and enhanced rank concepts. And for the first time we evaluate our proposed scheme based on the modeling of various probability distributions in the IoT environments with the lossy wireless link. Specifically, the proposed enhanced RPL based light-weight routing protocol improves the robustness with the multi-paths locally established based on the enhanced rank concepts even though lossy wireless links are existed. We showed the improvements of the proposed scheme up to $40 \%$ than the RPL based protocol.
\end{abstract}

Keywords: IoT(Internet of Thing), Hyper-Connectivity Communication, RPL(Routing Protocol for Low-Power and Lossy Networks), Light-Weight Routing Protocol

\section{사물 인터넷 기반 기기 간 통신 무선 환경에서 향상된 $\mathrm{RPL}$ 기반 경량화 라우팅 프로토콜}

오 하 영 ${ }^{+}$

\author{
요 약
}

\begin{abstract}
사물 인터넷 기반 초연결성 통신을 위한 일차적인 과제는 액서스 포인트, 기지국 등의 인프라를 거치지 않는 저전력, 손실 무선 네트워크 환경에서 사물 인터넷 기기들 간의 직접 통신 기법을 개발하는 것이다. 저전력 그리고 손실 네트워크 환경에서 사물 인터넷 디바이스들은 물론 라우터가 한정된 메모리를 사용하는 제한 조건을 가지고 있기 때문에 목적지 경로 정보를 지속적으로 유지할 수 없으며 다만 적은 수의 디폴 트 라우터 정보만을 유지한다. IPv6주소를 그대로 활용하고 단순히 제어 메시지들의 양만 줄이는 데 초점을 둔 기존 경량화 라우팅 기법들과 달리 본 연구에서는 블룸필터 및 향상된 랭크개념을 활용하여 경량화 자동 주소 설정을 포함한 IPv6 이웃노드탐색 기법 및 경량화된 라우팅 프로토콜을 제안한다. 또한, 처음으로 사물 인터넷 기반 기기 간 손실 있는 무선 환경을 다양한 확률분포함수를 따르면서 에러가 발생하도록 모델링하여 성능평가를 수행했다. 특히, 제안하는 기법은 동적으로 무선 링크가 변하여 데이터 손실이 발생해도 향상된 랭크 정보를 바탕으로 다중 경로 정보를 지역적으로 활용하여 견고성을 높였다. 성능평가 결과 제안하는 기법은 RPL 기반 라우팅 프로토콜에 비해서 최대 $40 \%$ 까지 성능향상을 보일 수 있었다.
\end{abstract}

키워드 : 사물 인터넷, 초연결성 통신, 저전력 그리고 손실 네트워크에서 라우팅, 경량화된 라우팅 프로토콜

\section{1. 서 론}

다양한 서비스들의 수요 및 최근 스마트 기기들의 발전

※ 이 논문은 2014년도 정부(미래창조과학부)의 재원으로 한국연구재단의 지원을 받아 수행된 기초연구사업(No. 한국연구재단에서 부여한 과제번 호: NRF-2014R1A1A1003562)의 일환으로 수행하였음.

† 정 회 원: 숭실대학교 정보통신전자공학부 조교수

Manuscript Received : August 27, 2014

First Revision : September 23, 2014

Accepted: October 13, 2014

* Corresponding Author:Hayoung Oh(hyoh@ssu.ac.kr)
등은 인간 중심이었던 인터넷을, 인간의 삶을 보다 스마트 하게 만드는 지능화된 사물 인터넷(Internet of Thing: IoT) 환경으로 변화시켰다. IoT가 응용될 수 있는 단말은 저전력, 초소형 및 경량적이어야 한다는 특성 때문에 지금까지 폐쇄 적이고 개별적으로 이용되어오던 센서 네트워크에 일차적으 
로 접목 가능하다[1][2]. 센싱된 정보가 스마트폰, 스마트 $\mathrm{TV}$ 와 같은 다양한 스마트 기기들과 연동된다면 새로운 개 인 중심의 생활밀착형 서비스를 제공할 수 있고, 특히 2020 년에는 약 240 억대의 단말이 인터넷에 연결될 수 있기 때문 에 이를 통해 스마트 홈, 스마트 그리드, 헬스케어, 지능형 교통서비스 등과 같은 IoT기반의 다양한 서비스가 창출될 수 있다.

물론, 최근 스마트 기기들은 가속도계, GPS, 근접센서, 카 메라 등 자체 내장된 센서 등을 활용하여 새로운 응용서비 스를 만들어 내는 능력과 프레임워크를 제공하고 있기 때문 에 사용자와 개발자의 편의에 따라 내장 센서의 값을 활용 할 수 있다. 하지만 스마트폰 센서의 크기나 가격, 제한된 공간 등으로 다양한 센서들을 모두 내장시킬 수는 없으며, 따라서 사용자들의 지속적인 욕구를 충족시키기엔 한계가 있다. 이런 이유로 인해 최근에는 사물 인터넷과의 연동을 통해 외부에 위치하고 있는 다양한 센서를 활용하여 정보를 수집하거나 스마트 기기에서 원격으로 제어 할 수 있는 기 술개발에 대한 관심과 논의가 뜨거운 상황이다. 일례로 이 동성을 가진 스마트폰들은 주변에 산재해 있는 고정된 다양 한 환경 및 기상 센서들로부터 정보를 수집하여 현재 위치 의 실시간 온 - 습도를 포함한 환경 정보를 다양하게 활용할 수 있다[2].

사물 인터넷의 3대 주요 기술은 센싱 기술, 유무선 통신 및 네트워크 인프라 기술, 서비스 인터페이스 기술이다[1]. 센싱 기술은 센서로부터 정보를 수집 - 처리 - 관리하고 정보 가 서비스로 구현되기 위한 기법들을 지원한다. 네트워크 종단간(end-to-end)에 사물 인터넷 서비스를 지원하기 위해 서는 근거리 통신기술(WPAN, WLAN 등), 이동통신기술 ( $2 \mathrm{G}, 3 \mathrm{G}$ 등)과 유선통신기술(Ethernet, $\mathrm{BcN}$ 등) 등의 유무 선 통신 및 네트워크 인프라 기술이 필요하다. 최종적으로 사용자에게 사물 인터넷 서비스를 제공하기 위해서는 정보 를 센싱, 가공/추출/처리, 저장, 판단, 상황 인식, 인지, 보안/ 프라이버시 보호, 인증/인가, 디스커버리, 객체 정형화, 오픈 $\mathrm{API}$, 오픈 플랫폼 기술 등을 포함하는 서비스 인터페이스 기술이 필요하다.

최근에는 인프라가 없는(Infra-less) 환경에서 디바이스들 끼리 정보를 직접 주고받을 수 있는 기기 간 직접(deviceto-device) 통신기술들이 다양한 무선망에서 발전되어 오고 있다[3-6]. 셀룰러 네트워크에서는 기기 간 직접통신 기술로 써 3GPP에서 LTE(Long-Term Evolution)에 직접통신을 적 용하기 위해 최근 표준화를 시작했고[4][5], 비면허 대역에서 는 기존의 무선랜 표준을 확장하여 와이파이 다이렉트의 $802.11 u$ 기술이 개발되었다[6][7]. 또한 IEEE 802.15.8에서는 대상인식 통신 표준화 작업이 진행 중이다. 기기 간 직접통 신의 대표적인 장점들은 i) $\mathrm{AP}$ 및 기지국등과 같은 중간노 드를 거칠 필요가 없기 때문에 전송횟수, 통신거리 및 지연 시간 감소를 시킬 수 있고, ii) IoT단말기들끼리 센싱된 정 보, 이웃탐색 및 IPv6주소 등의 새로운 종류의 근접 기반 자원들도 서로 쉽게 공유할 수 있는 환경을 새로 만들 수 있다는 점 등을 들 수 있다[8].

하지만, IoT환경에서는 단말기가 특히 저전력, 경량화 및 불안정한 통신 상황등 이란 특성들을 가지기 때문에 기존의
자동 주소 설정을 포함한 IPv6 이웃발견(Neighbor Discovery) 기법, 기기 간 통신 및 라우팅 프로토콜과 다르게 디자인되 야 한다.

근접 기반 경량화 자동 주소 설정 및 IPv6 이웃 발견기 법은 두 개 이상의 IoT 단말기들이 물리적으로 근접한 위치 에 있을 때 각 IoT 단말기가 경량화된 IPv6주소를 자동으로 설정하고 상대 IoT를 발견 후 기반 시설을 거치지 않고 IoT 기기 간 직접통신을 하는 것이다. 이러한 근접 기반 경 량화 자동 주소 설정 및 IPv6 이웃 발견기법을 구현하기 위 해서는 우선적으로 수많은 주변 IoT들이 자동으로 각각 설 정한 IPv6주소가 겹치지 서로 겹치지 않는지 찾아내는 디스 커버리 프로토콜을 설계하는 것이 매우 중요하다. 하지만, 적절한 시간 내에, 가능한 적은 양의 무선 자원을 사용하고, 배터리 소모를 최소화하면서 경량화 자동 주소 설정을 탐색 하고 목적지까지 데이터를 전송해줄 수 있는 프로토콜을 설 계하는 것은 간단한 일이 아니다[10-15].

특히, 이러한 방식으로 수많은 IoT 기기들이 원하는 IoT 단말기 및 중복되지 않은 IPv6주소를 발견하지 못하거나 목 적지까지 경로 유지가 되지 않을 경우 접속을 끊고 다시 연 결해야하는 과정을 반복해야 하고 이러한 과정에서 많은 양 의 유니캐스트 정보가 전달되야 하므로 매우 비효율적이라 할 수 있다.

오버헤드를 줄이기 위한 기존 연구들로는 데이터 전송 측 면에서 해결책을 제시한 $\mathrm{CoAP}$ (Constrained Application Protocol) [16]과 제어 메시지를 줄이기 위한 RPL(Routing Protocol for Low-power and Lossy Networks) [8], Kunjan Patel [17], PSR [18] 및 $\mathrm{Hu}$ She [19]등이 있다. 기존 연구 들은 데이터를 목적지로 경량화하게 전송하기 위해서 제어 메시지 타입을 다양하게 구분하거나 제한된 시간 동안만 비 콘을 주기적으로 주고받아 데이터 전송 전체 경로를 설정하 는 데 초점을 맞추었다.

반면 제안하는 기법은 해시함수(hash function) 기반블룸 필터 표현법을 활용하여 노드들끼리 주고 받는 메시지양을 줄이는 것을 물론 노드식별주소, 이웃 발견 및 라우팅 경로 등을 경량화하게 모두 표현하여 궁극적으로 전체 제어 메시 지의 오버헤드를 줄이는 것을 목표로 한다. 저전력 손실 네 트워크에서 경량화된 주소를 가진 IoT 단말기들이 RPL (Routing Protocol for Low-power and lossy networks) [8] 기반으로 동작할 때 루프[9], 경로 손실등과 같은 문제가 생 겨도 유연하고 작은 오버헤드로 경로를 다시 재탐색하여 빠 른 시간 내에 원하는 이웃 IoT단말기를 찾아 목적지까지 데 이터를 견고하게 전송할 수 있다.

제안하는 IoT 단말기의 경량화 자동 주소 설정, IPv6 이 웃 발견 기법 및 경량화(light-weight) 라우팅 프로토콜은 특정 통신 기술을 가정하고 있지는 않기 때문에 와이파이 다이렉트나 IEEE 802.15.8 대상인식통신 등에 추후 응용될 수 있을 것이다.

본 논문의 구성은 다음과 같다. 2 장에서 관련연구를 소개 한다. 3장에서는 사물 인터넷 기반 기기간 통신 무선 환경 에서 향상된 RPL기반 경량화 라우팅 프로토콜 대하여 설명 한다. 4장에서는 성능평가 결과를 보여주며, 마지막으로 5 장 에서는 본 논문을 정리하며 마친다. 


\section{2. 관련 연구}

IoT기반 저전력 통신을 위한 라우팅 프로토콜은 경로설 정을 위한 제어메시지관점(control plane) 및 데이터 전송관 점(data plane)에 따라 크게 표 1과 같이 나뉠 수 있다.

\subsection{CoAP(Constrained Application Protocol)}

$\mathrm{M} 2 \mathrm{M}$ 관련 표준화가 가속화 되어가고 있는 가운데, IETF (Internet Engineering Task Force) 내의 CoRE(Constrained RESTful Environments) 워킹그룹에서는 2010년부터 6LoWPAN 의 상위 애플리케이션 계층 프로토콜 $\operatorname{CoAP}($ Constrained Environments Application Protocol)의 표준화 활동을 시작해왔다. 그림. 1 은 $\mathrm{CoAP}$ 가 $\mathrm{M} 2 \mathrm{M}$ 관련 표준 아키텍처 중 어디에 위치하는 지를 보여준다[16].

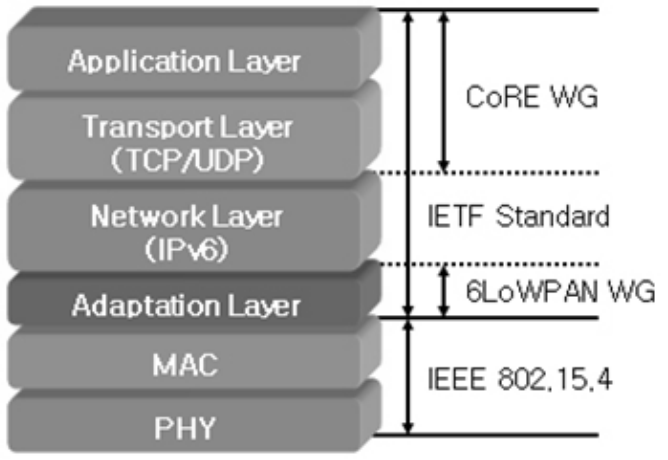

Fig. 1. CoAP in M2M related architecture

그림. 1에서 볼 수 있듯이 물리계층(PHY)와 매체접근계 층(MAC)은 저전력 센서노드를 위한 IEEE 802.15.4 표준을 기반 표준으로 삼고 있고, 네트워크 계층인 IPv6 프로토콜 과 IEEE 802.15.4 표준과의 인터페이스를 위한 적응 계층 (Adaptation)으로 $6 \mathrm{LoWPAN}$ 프로토콜이 위치하고 있다. $\mathrm{CoAP}$ 는 이러한 표준들 상위의 트랜스포트와 애플리케이션 계층을 위한 응용 프로토콜이다.
$\mathrm{CoAP}$ 을 적용할 수 있는 대상 노드들은 노드가 저성능의 $\mathrm{CPU}$ 를 가질 뿐만 아니라 작은 용량의 램 및 롬 을 가지는 제한적인 노드를 대상으로 하고 있다. 또한, 사물 인터넷을 구성하는 기기들의 상태 전송이라는 이벤트를 비동기적으로 전송할 수 있는 Representational State Transfer(REST) 아 키텍처를 기반으로 Resource Discovery, 멀티캐스트 지원, 비동기 트랜잭션 요청 및 응답 등을 지원하기 위한 프로토 콜이다.

특히, $\mathrm{CoRE}$ 워킹그룹에서 제정하려는 $\mathrm{CoAP}$ 의 표준화 영 역은 $\mathrm{TCP}$ 와 $\mathrm{UDP}$ 를 포함하는 트랜스포트 계층을 포함한 상위 애플리케이션 계층에서 $\mathrm{M} 2 \mathrm{M}$ 노드들 사이에서 어떻게 리소스 이벤트(예: 온도, 습도)에 대한 요청을 하고 이벤트 가 생겼을 경우 어떻게 비동기적으로 리소스 이벤트를 노드 에게 전송할 지에 대한 방법을 설계하는 부분이다.

$\mathrm{HTTP}$ 를 이용하기는 하지만 $\mathrm{CoAP}$ 이 기존의 HTTP와 다른 점은 $\mathrm{UDP}$ 환경 하에서 유니캐스트와 멀티캐스트 양쪽 을 지원해야 한다는 점과 $\mathrm{CoAP}$ 은 경우에 따라 노드가 클라 이언트, 서버, 프록시의 역할을 할 수 있다는 것이다.

\subsection{RPL(Routing Protocol for Low-power and Lossy Networks)}

RPL(IPv6 Routing Protocol for Low-power Lossy Networks)은 IETF의 ROLL(Routing Over Low-power and Lossy networks) 워킹 그룹에서 표준화를 진행 중인 IPv6 라우팅 프로토콜로 Ripple(리플)이라 읽는다. RPL은 IEEE 802.15 .4 [14], 전력선 통신등 저전력과 잡음이 매우 심한 네 트워크 환경에 적합하도록 설계되었으며, 여러 응용들의 다 양한 요구사항을 수용하기 위해 다양한 라우팅 메트릭을 지 원한다. 이를 위하여 각 응용의 요구조건을 달성하기 위한 라우팅 메트릭, 경로 최적화 등에 해당하는 기능은 Objective Function $(\mathrm{OF})$ 이라 하여 분리하였으며 표준에서 정의하는 내 용들은 다양한 $\mathrm{OF}$ 에 공통적으로 사용하는 일반적인 내용들 을 정의하고 있다[8].

$\mathrm{RPL}$ 객체는 그림. 2 와 같이 목적지 기반 방향성은 있지만 사이클이 없는 여러 개의 그래프(DODAGs: Destination Oriented Directed Acyclic Graphs)로 구성된다. 노드의 랭크는 그림.

Table 1. IOT based protocols for Low-power communications

\begin{tabular}{|c|c|}
\hline Data Plan & Control Plane \\
\hline $\begin{array}{l}\text { 6LoWPAN (IPv6 over Low-power WPAN) } \\
\text {-Fragment Forwarding Technique }\end{array}$ & \multirow{2}{*}{$\begin{array}{l}\text { RPL (Routing Protocol for Low-power and Lossy Networks) } \\
\text { - Each node builds a directed acyclic graph through which packets } \\
\text { can be efficiently routed to sink nodes. } \\
\text { - From the sink, RPL builds routes to nodes inside the network } \\
\text { which can distribute data to sensor nodes. } \\
\text { - ContikiMAC used as radio cycling protocol. } \\
\text { - Energy consumption is measured using Contiki's built-in power } \\
\text { profiler. }\end{array}$} \\
\hline $\begin{array}{l}\text { - M2M communication in constrained networks } \\
\text { - Connect smart objects to the Internet } \\
\text { - A bulk data transfer mechanism over UDP } \\
\text { - Avoid fragmentation, retransmission of TCP to minimize state } \\
\text { maintenance and power usage } \\
\text { - Its own loss detection and retransmission to avoid the problems } \\
\text { TCP has in wireless networks } \\
\text { - Goal: HTTP equivalent for WSNs (Representational State } \\
\text { Transfer: REST) }\end{array}$ & \\
\hline
\end{tabular}


3과 같이 루트 DODAG로부터 얼마나 멀리 위치하고 있는 지를 알려준다. DODAGs 를 만들기 위해 각 노드들은 로컬 링크 정보 및 랭크를 담은 DAG Information Object(DIO)라 는 제어메시지를 주기적으로 보낸다. $\mathrm{DIO}$ 를 수신한 노드들 은 DODAG루트까지 최소의 비용으로 전송할 수 있는 부모 노드를 선택하기 위해서 새로운 DODAG에 참여하거나 기 존의 $\mathrm{DODAG}$ 를 유지한다. 그림. 4 는 $\mathrm{DIO}$ 메시지외에 RPL이 동작하는데 필요한 추가적인 제어 메시지들의 종류를 보여 준다.

$\mathrm{RPL}$ 은 크게 데이터 저장 금지 모드(non-storing mode), 데이터 저장 가능 모드(storing mode) 및 데이터가 위로 전 송되는 것을 막는 기법 이렇게 3 가지 전송기법이 있다. 저 장 금지 모드에서는 근접한 말단 노드들끼리 통신을 하고자 하는 경우에도 DODAG루트까지 올라갔다가 데이터가 수신 노드에게 전송되야한다는 특징이 있고, 저장 모드에서는 루 트까지 올라가지 않아도 공유하고 있는 근접 상위노드만 통 과하여 해당 노드에게 데이터를 전송할 수 있다는 특징이 있다. 하지만 어떤 타입이든 RPL에서는 아래와 같이 3가지 의 문제가 발생한다.

- $\mathrm{RPL}$ 기법에서는 노드들이 에너지를 절약하기 위해서 잠자는 모드(sleeping mode)로 들어가서 제 때 응답을 안 하 거나 저전력 및 데이터 손실이 존재할 수 있는 환경이기 때 문에 데이터 성공율 매우 낮은 편이다. 결과 데이터 전송에 문제가 생긴 경우 $\mathrm{DIO}$ 제어메시지를 활용하여 문제를 알리 고 해결한다.

- RPL에서는 루프문제(loop problem)를 완벽하게 해결 할 수 없다. 따라서 loop이 발생되면 실시간으로 탐지하여 문제 있는 부분을 유연하게 피하고(loosely avoidance) DIO, $\mathrm{DIS}$ 및 $\mathrm{DAO}$ 제어메시지들을 활용하여 작은 오버헤드로 최 대한 빨리 해결 하는 게 필요하다. 예를 들어서 RPL에서는 랭크가 감소하는 부분으로만 데이터가 전송 되야 루프(loop) 이 발생되지 않는 것을 의미한다. 만약 어느 순간 랭크가 증가되는 쪽으로만 데이터가 전송된다면 이는 loop이 발생 될 확률이 높아질 수 있다는 것을 의미한다. 따라서 각 응 용의 요구조건을 달성하기 위한 라우팅 메트릭, 경로 최적 화 등에 해당하는 기능인 Objective Function $(\mathrm{OF})$ 을 잘 디 자인하여 문제가 생긴 부분만 지역적으로 해결하던지 아니 면 전체적으로 해결해야할지 결정해야한다.

- RPL은 ISA 100.11a혹은 wireless HART등에 비해서 동적으로 변화하는 환경(dynamic environment)에서 데이터 를 저전력으로 전송할 수 있는 기법을 제안했다. 하지만 여 전히 끈어짐에 대한 대응방법이 매우 약하다. 비록 문제가 발생했을 경우 DIO poisoning이라는 방식으로 문제를 해결 하려고 하지만 문제가 생길 때마다 매번 DODAG들을 새로 유지하고 업데이트하는데 오버헤드가 들기 때문에 완벽한 해결책이 되지 못한다.

저전력 손실 네트워크을 구성하는 $\mathrm{LLN}(\mathrm{Low}-$ power and Lossy Networks) 라우터는 한정된 메모리를 사용하는 제한 조건을 가지고 있기 때문에 목적지 경로 정보를 유지할 수 없으며 다만 적은 수의 디폴트 라우터 정보만을 유지한다. 예 를 들어, IEEE 802.15.4 상에서 IPv6 기반 네트워크 프로토콜 표준화에서는 저전력, 저가, 저 기능(8bit-microporcessors, 수 $\mathrm{KB} \mathrm{RAM})$, 저속( $250 \mathrm{kbps})$ 의 제한된 환경을 고려하 고 있으며 제한된 단말기(constrained device)를 정의할 수 있는 그룹은 사이즈 및 역할 별 표 2, 표. 3 과 같다.

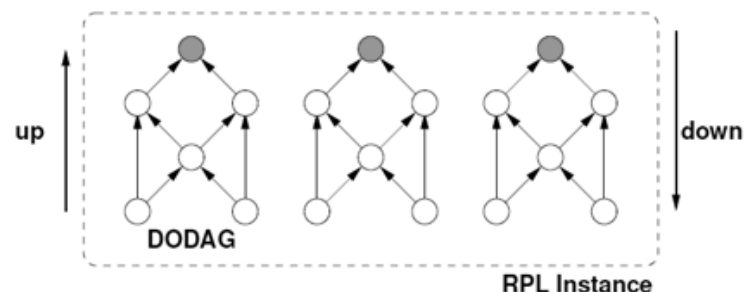

Fig. 2. RPL object and destination based DODAGs: Destination Oriented Directed Acyclic Graphs

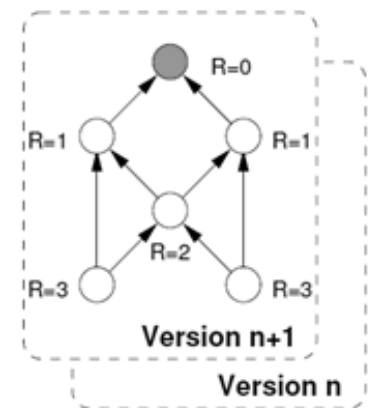

Fig. 3. Rank and version definitions of DODAGs

DAG Information Object (DIO)
- A DIO carries information that allows a node to discover
an RPL Instance, learn its configuration parameters and
select DODAG parents
DAG Information Solicitation (DIS)
- A DIS solicits a DODAG Information Object from an RPL
node
Destination Advertisement Object (DAO)
- A DAO propagates destination information upwards along
the DODAG

Fig. 4. RPL control messages

Table 2. Device classifications based on the limited memory size

\begin{tabular}{l|l|l}
\hline & Data Size & Code Size \\
\hline Class 1 & $\sim 10 \mathrm{~KB}$ & $\sim 100 \mathrm{~KB}$ \\
\hline Class 2 & $\sim 50 \mathrm{~KB}$ & $\sim 250 \mathrm{~KB}$ \\
\hline
\end{tabular}

Table 3. Device role based classification with the limited memory

\begin{tabular}{|c|c|c|}
\hline Constrained nodes & $\begin{array}{l}\text { Nodes talking to } \\
\text { constrained nodes }\end{array}$ & $\begin{array}{c}\text { Gateways/ } \\
\text { Proxies }\end{array}$ \\
\hline - Sleepy nodes & $\begin{array}{l}\text { - To sleepy nodes } \\
\text { - Normally always } \\
\text { alive }\end{array}$ & $\begin{array}{l}\text { - To sleepy nodes } \\
\text { - Could be always } \\
\text { alive }\end{array}$ \\
\hline
\end{tabular}

따라서 제한된 환경에서도 LLN 라우터가 LLN 내에 목 적지까지의 연결성 정보 및 데이터그램 전달을 위한 경로 정보를 유지해야 한다. 더불어 데이터그램 전달을 위해 IPv6 소스 라우팅이 필요하다. 따라서 본 연구에서는 Infra- 
less 환경에서 RPL 라우팅 도메인 내에서 RPL 라우터들끼 리 데이터그램 전달을 위해 IoT 단말기의 경량화 자동 주소 설정을 포함한 IPv6 이웃 발견 기법 및 light-weight 라우 팅 프로토콜 개발하는데 목표를 둔다.

\section{3 기타 경량화 라우팅 프로토콜}

Kunjan Patel [17]은 센서 네트워크에서 유니캐스트 수행 시 다양한 응답 메시지(acknowledgement)들과 한정된 시간 내(timeout schemes)에서만 라우팅 프로토콜이 동작하게 하 여 불필요한 메시지 양을 줄이는 경량화 라우팅 프로토콜을 제안했다. 하지만 제한된 시간동안에만 데이터를 전송할 수 있기 때문에 성능향상에 한계가 있고 다양한 응답 메시지를 주기적으로 주고 받아야하기 때문에 총 전달되는 제어 메시 지 양은 여전히 많다.

[18]에서는 모바일 무선 네트워크 환경에서 소스에서 목 적지까지 모든 경로를 알 수 있는 경량화 된 소스 라우팅 프로토콜(PSR: A Lightweight Proactive Source Routing Protocol For Mobile Ad Hoc Networks)을 제안했다. 이 기 법은 작은 오버헤드로 토폴로지에 대한 많은 정보를 활용할 수 있도록 이진트리 기반 라우팅 프로토콜 상에서 동작한 다. 하지만 이진트리 구조로 변형이 가능한 토폴로지에서만 동작한다는 한계점이 있으며 물리적으로 주어진 토폴로지를 이진 트리화하기 위해서 필요한 제어 메시지 양들을 고려하 면 역시 총 전달되야 하는 제어 메시지 양이 여전히 크다는 것을 알 수 있다.

$\mathrm{Hu}$ She [19]는 자동차 무선 네트워크 환경에서 실시간으 로 발생하는 트래픽 지역적 정보를 경량화하게 수집하는 기법을 제안했다. 이를 위해 주기적인 비콘 메시지로 링크 상태를 측정하고 데이터를 효율적으로 전달하는 기법을 제 안했다. 움직이는 자동차 무선 네트워크 환경에서 최소의 전송 횟수로 데이터를 목적지로 성공적으로 전송할 수 있 지만 이를 위해 주기적으로 제어 메시지를 주고받아 링크 상태를 확인하고 저장해야하기 때문에 역시 총 전달 및 저 장되야하는 제어 메시지 양은 많이 줄이지 못했다는 한계점 을 지닌다.

기존 연구들은 데이터를 목적지로 경량화하게 전송하기 위해서 제어 메시지 타입을 다양하게 구분하거나 주기적으 로 주고받아 데이터 전송 전체 경로를 설정하는 데 초점을 맞추었다.

반면 제안하는 기법은 블룸필터 표현법을 활용하여 노드 들끼리 주고받는 메시지 양을 줄이는 것을 물론 노드식별주 소, 이웃 발견 및 라우팅 경로 등을 경량화하게 모두 표현 하여 궁극적으로 전체 제어 메시지의 오버헤드를 줄였다. 특히 제안하는 기법에서는 사물 인터넷 기반 기기간 통신 환경에서 다양한 확률 모델을 바탕으로 데이터 손실이 많은 채널 상황을 처음으로 구성하여 성능평가를 수행했으며 데 이터 손실이 발생해도 즉시 향상된 랭크 기법을 고려하여 지역적으로 다양한 다중 경로를 찾을 수 있기 때문에 기존 의 RPL라우팅 프로토콜보다 최대 $40 \%$ 성능향상이 있음을 알 수 있다.

\section{3. 사물 인터넷 기반 기기간 통신 무선 환경에서 향상된 RPL기반 경량화 라우팅 프로토콜}

3.1 블룸필터(Bloom filter)와 향상된 랭크기법 기반 경량화된 IPV6 주소 설정 및 경량화 라우팅 프로토콜

IoT단말기들이 급격하게 증가되고 초연결성을 지원하기 위해서는 센싱데이터, IPv6주소 및 이웃탐색 등의 주고받는 메시지 양이 급격하게 증가될 것이다. 반면 IoT단말기들 및 LLN라우터들은 초경량화, 저전력 및 손실등의 특성이 있기 때문에 최소한의 데이터를 저장하고 있어야하고 목적지까지 일관된 경로로 데이터를 전송하는 것은 어려운 일이다. 따 라서 노드식별자에 주소를 압축하여 의미는 부여하되 경량 화 된 표기법이 필요하다.

경량화 된 $\mathrm{IPv} 6$ 주소 설정을 위해 본 연구에서는 블룸필 터 및 향상된 랭크기법을 활용한다. 기존의 RPL기법에서는 데이터 전송 레벨을 구분하기 위해 랭크(rank)라는 루트노 드로부터 깊이가 얼마나 되는지 나타내는 척도만 활용했다. 하지만 본 논문에서는 그림. 5와 같이 상대적인 부모로부터 자식노드의 위치를 구분해주는 2 번째 새로운 첨자(index)인 상대적 위치(relative location) 정보를 새로 추가한 향상된 랭크라는 개념을 제안한다. 예를 들어 $(3,0)$ 은 랭크가 3 이고 상대적인 부모노드 $(2,0)$ 으로부터 왼쪽에 위치한 노드를 의미 한다. 반면에 $(3,1)$ 은 랭크가 역시 3 이지만 $(2,0)$ 노드로부터 오른쪽에 위치한 노드를 의미한다.

$\mathrm{RPL}$ 기법에서는 같은 rank를 가진 이웃노드는 루트노드로 부터 해당 IoT노드까지 동일한 레벨에 존재한다는 것을 의 미한다. 따라서 루프를 피하고 견고하게 데이터를 전송하기 위해서는 rank가 낮은 이웃 노드들만 고려할 수 있다. 제안 하는 향상된 RPL (enhanced RPL : eRPL)기법에서는 rank 는 같거나 낮은 조건에서 relative location값이 같거나, 크거 나, 작아지거나 상관없이 다양한 조합을 반복하면서 견고한 경로로 데이터를 전송할 수 있도록 만들어준다. 그림. 5 에서 알 수 있듯이 제안하는 기법에서는 경량화된 IPv6주소를 활 용하여 각 소스 노드에서 목적지 경로까지 총 3 개의 다중 경로를 활용할 수 있다는 것을 보여준다.
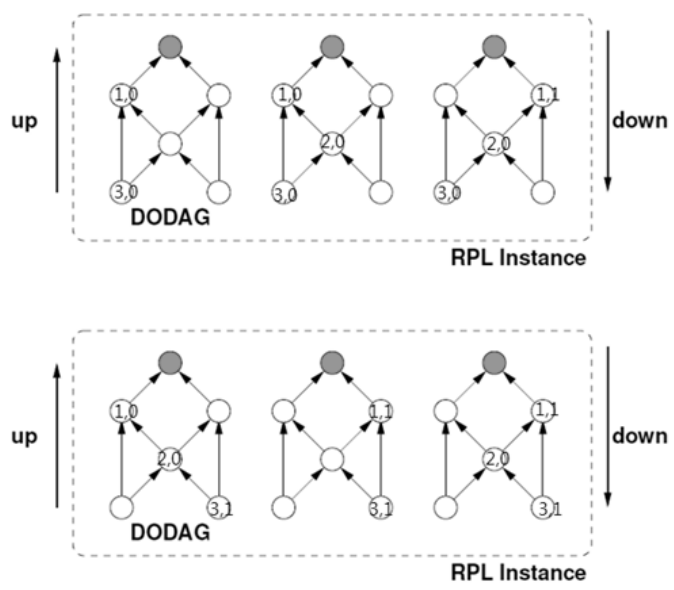

Fig. 5. An enhanced RPL based light-weight routing protocol 
그림. 6(a)는 블룸필터 결과 생성된 노드 구분자들을 바탕 으로 IPv6주소를 대신하여 노드를 식별하는 과정을 보여준 다. 예를 들어, 1 번, 6 번 및 10 번 자리에 ' 1 '비트로 설정된 경 우 노드 1을, 1 번, 3 번 및 7 번 자리에 '1'비트로 설정되면 노 드 2번, 2 번, 3 번 및 8 번 자리에 '1'비트로 설정되면 노드 3 번을 나타낸다. 만약 소스에서 목적지까지 노드 1 번, 2 번 및 3 번을 경유하여 경로설정 제어 메시지 패킷이 전송됐다면 목적지가 가지고 있는 블룸필터는 $1,2,3,6,7,8,10$ 번 자리에 모 두 '1'비트로 설정된 최종 결과만 가지고 있게 된다. 목적지 는 자신의 원 홉 반경 내의 주변 노드들 중 어떤 노드를 경 유하여 경로설정 제어 메시지 패킷이 전송됐는지 판단하기 위해 최종 블룸필터에 ‘ 1 '비트로 체크된 자리들과 각 이웃 노드들의 블룸필터를 대입하여 판별한다.

그림. 6(b)는 소스에서 목적지까지 데이터를 전송할 수 있는 다양한 경로가 존재할 때 각 노드를 10 비트의 블룸필 터로 표현한 멀티 홉 시나리오를 보여준다. 그림. 6(c)는 소 스에서 목적지 노드의 전 노드인 $(1,0)$ 까지 데이터를 전송할 수 있는 각각의 다중 경로들을 블룸필터 테이블에서 관리하 는 과정을 보여준다.

하지만, 블룸필터 값만으로는 중복되거나 노드 식별 정확 도가 떨어질 수 있기 때문에 제안하는 기법에서는 상대적인 자녀노드의 위치를 표현할 수 있는 향상된 랭크를 추가로 활용하여 이 문제를 해결한다. 해당 코드에는 이웃노드들의 이름 집합을 축약한 정보만이 담겨 있으므로 코드로부터 이 웃노드들 이름을 유일하게 복구할 수 없다. 대신 특정 이웃 노드의 이름이 송신자의 이웃노드리스트 집합에 포함되었는 지의 여부만 알 수 있다. 따라서 축약된 블룸필터 코드를 이용하여 이웃노드의 존재 유무를 테스트할 때 정보의 손실 로 인해 오류가 발생 할 수 있다. 이웃노드가 존재하지 않 지만 존재한다고 판단한 경우는 거짓 양성(false positive) 오류가 발생했다고 할 수 있으며 이웃노드가 존재하지만 존 재하지 않는다고 판단한 경우는 거짓 음성(false negative) 오류로 분류할 수 있다. 이때, 이웃노드 발견이 실패하는 경 우를 막기 위해서 거짓 음성 오류가 발생하지 않도록 향상 된 랭크를 반영하여 축약된 블룸필터 코드를 설계했다. 즉, 같은 블룸필터에 속한 여러 개의 이웃 노드들이 존재해도 부모 노드로부터 각 자식 노드들의 상대적인 위치는 다르기 때문에 이를 표현하고 있는 향상된 랭크 식별자는 블룸필터 의 부정확성을 해결해줄 수 있다.

결과, 제안하는 기법에서는 전체경로 및 상대적인 자식 위치를 함축하고 있는 블룸필터를 활용하여 경량화된 IPv6 주소, 이웃 노들 발견 및 경량화 라우팅 프로토콜 설 정할 수 있다. 기존 RPL기법과 달리 제안하는 기법에서는 각 부모 노드가 블룸필터로 함축화 된 다양한 자식경로들 을 유지하기 때문에 손실이 많은 사물 인터넷 기반 무선 네트워크에서 다양한 에러가 많이 발생해도 바로 다른 지 역적으로 가능한 경량화 된 경로를 활용하여 견고성을 높 인다.

\section{2 블룸필터(Bloom filter) 기반 경량화된 이웃탐색 기법}

일반적으로 근접 단말기의 발견을 위해 통신 단말기는 자 신의 식별자(identifier)가 포함되어 있는 비콘(beacon) 등의 신호를 주기적으로 방송해야하고 이웃노드들의 발견을 위해
Target data = "node1, node2, node3" Key = "node1", "node2", "node3"

\begin{tabular}{|c|c|c|c|c|c|c|c|c|c|c|}
\hline $\begin{array}{l}\operatorname{Hash} 1(\text { node } 1)=1 \\
\text { Hash } 2(\text { node } 1)=10 \\
\text { Hash } 3(\text { node } 1)=6\end{array}$ & \multicolumn{5}{|c|}{$\begin{array}{l}\text { Hash } 1 \text { (node } 2)=7 \\
\text { Hash } 2(\text { node } 2)=1 \\
\text { Hash } 3(\text { node } 2)=3\end{array}$} & \multicolumn{5}{|c|}{$\begin{array}{l}\text { Hash } 1(\text { node } 3)=8 \\
\text { Hash } 2(\text { node } 3)=3 \\
\text { Hash } 3(\text { node } 3)=2\end{array}$} \\
\hline Node1 & 1 & 0 & 0 & 0 & 0 & 1 & 0 & 0 & 0 & 1 \\
\hline Node2 & 1 & 0 & 1 & 0 & 0 & 0 & 1 & 0 & 0 & 0 \\
\hline Node3 & 0 & 1 & 1 & 0 & 0 & 0 & 0 & 1 & 0 & 0 \\
\hline Node1, Node2, Node3 & 1 & 1 & 1 & 0 & 0 & 1 & 1 & 1 & 0 & 1 \\
\hline \multicolumn{11}{|l|}{ Test key $=$ "Node1" } \\
\hline Node2 & 1 & 0 & 1 & 0 & 0 & 0 & 1 & 0 & 0 & 0 \\
\hline
\end{tabular}

(a)

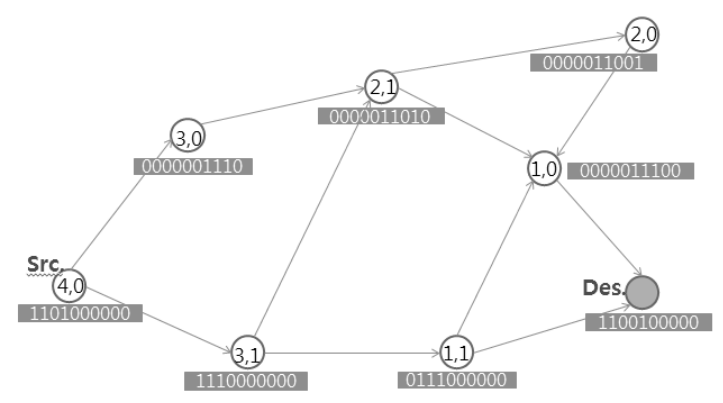

(b)

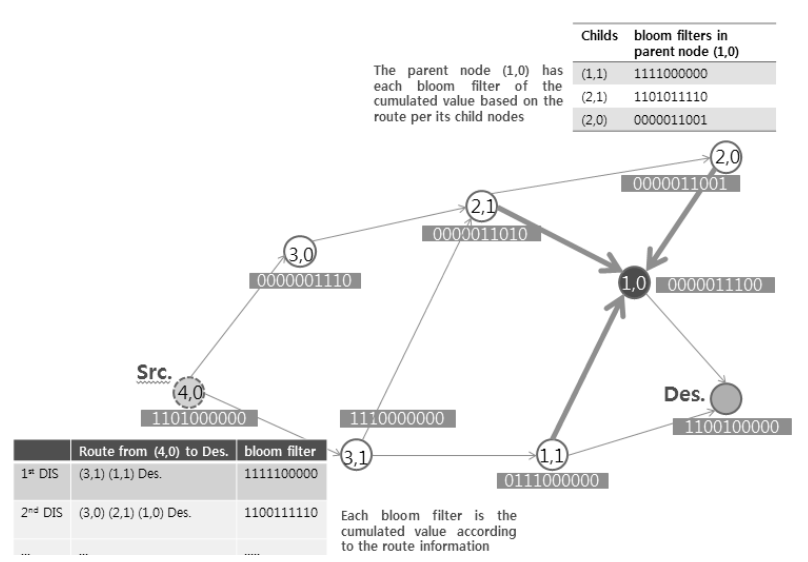

(c)

Fig. 6. (a) Bloom filter based light-weight IPV6 address,

(b) The multi-hop scenario with Bloom filter based light-weight IPv6 addresses (c) Light-weighted various routing routes establishment in eRPL

서는 추가적으로 이웃노드들의 정보가 포함된 메시지도 알 려야 한다. 그러나 이웃노드들의 이름 및 리스트를 그대로 방송하면 너무 많은 양의 정보를 전달하게 되어 저전력 손 실 네트워크에서는 적합하지 않다.

제안하는 기법에서는, 이웃노드 리스트 광고에 필요한 비 트수를 줄이기 위해 소스와 목적지 사이에 설정된 경로상의 이웃 노드들에 대한 정보를 그림. 6(c)의 축약된 블룸필터 코드로 표현하여 블룸필터 테이블에서 관리한다. 예를 들어, 노드 $(1,0)$ 의 블룸필터기반 이웃관리 테이블에는 자식 노드 들인 $(2,1),(2,0),(1,1)$ 및 목적지 노드가 들어있다. 노드 $(1,0)$ 은 목적지 노드만 제외하고 각 자식노드들의 상대적인 위치를 고려한 노드 블름 필터 값과 해당 노드까지 데이터 
를 전송될 때 거쳐 온 노드들의 전체 경로를 함축한 블룸 필터 값을 테이블에 관리한다. 만약 노드 $(1,0)$ 이 1111000000 라는 블름 필터로 데이터를 받았다면 노드 $(1,0)$ 의 주변 노 드들의 블름 필터 (0000011010), (0111000000) 및 (0000011001) 중에서 (1,1)에 해당되는 (0111000000)만 포함할 수 있기 때 문에 데이터가 소스, $(3,1),(1,1)$ 을 거쳐서 $(1,0)$ 으로 왔다는 것을 알 수 있다.

\section{4. 성능 평가}

성능평가를 위해 event-driven simulator중 하나인 NS-3 (Network Simulator-3)를 활용하여 그림. 6(c)와 같은 저장 금지 모드 및 저전력 손실 멀티 홉 네트워크 시나리오에서 제안한 기법을 평가했다. 손실 네트워크 환경을 만들기 위 해서 링크 전송 실패 확률이 normal, $\log -$ normal 또는 mixed distribution을 따르는 다양한 시나리오를 고려했으며 데이터 전송 경로가 없는 경우 지역적으로 (local repair scheme)

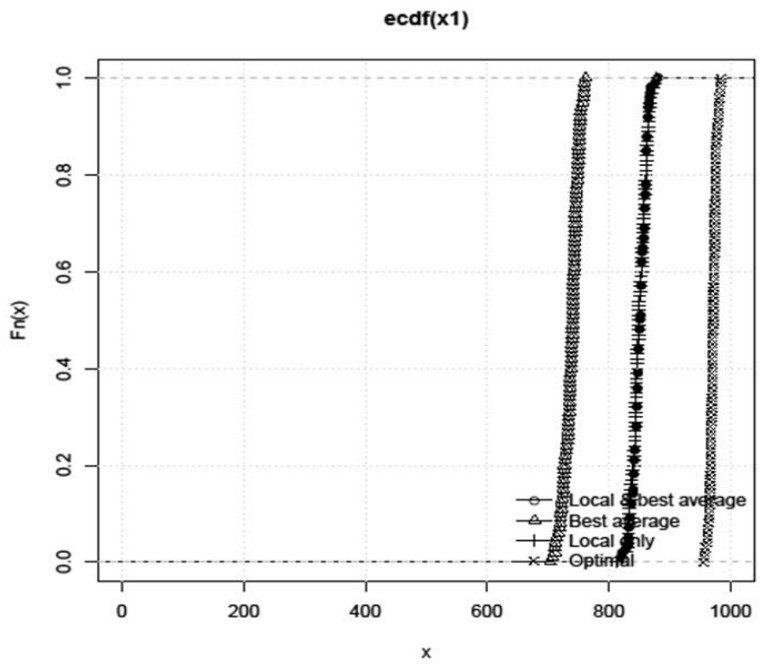

Fig. 7. CDF with the normal distribution of wireless link errors

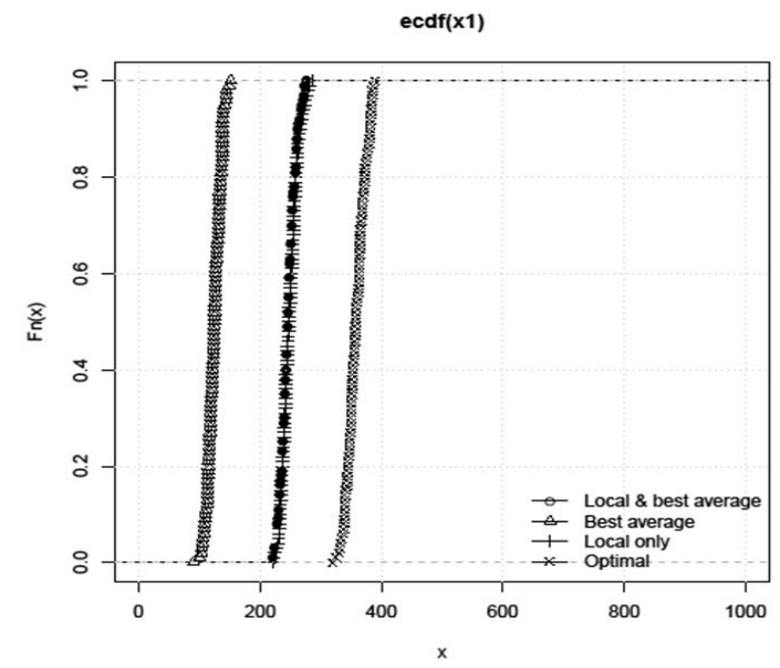

Fig. 8. CDF with the log-normal distribution of wireless link errors
혹은 전체적으로 (best average repair scheme) 혹은 두 기 법을 동시에 활용(local \& best average repair scheme)하여 $\mathrm{DODAG}$ 루트까지 경로를 재설정하여 데이터를 재전송을 시 도하도록 했다.

Local repair scheme은 일종의 greedy한 방식으로 이웃 노드 무선 링크들 중에서 제일 좋은 링크만 선택하는 기법, best average scheme은 소스에서 목적지까지 전반적으로 무선링크가 좋은 경로를 선택하는 기법 그리고 best average 및 local \& best average repair scheme은 두 기법이 혼합 된 경우다.

$\mathrm{RPL}$ 기법은 전체적으로 $\mathrm{DODAG}$ 를 여러 버전을 만들고 랭크를 설정한 (best average repair scheme) 기법에 해당된 다. 하지만 노드가 랜덤으로 잠자는 모드, 링크 채널 에러 및 루프문제를 발생시킨다고 가정했을 때 에러를 동적으로 극복하는데 한계가 있다. 반면 제안하는 기법(local \& best average repair scheme)은 상대적인 위치를 고려한 향상된 랭크를 바탕으로 다중 경로를 활용할 수 있는 지역적 해결 기법(local repair scheme)을 추가로 고려했기 때문에 최대 $40 \%$ 성능의 이득이 크다.

그림. 7은 무선 링크 에러가 normal distribution을 따를 때 누적분포함수를, 그림. 8은 무선 링크 에러가 $\log$-normal distribution을 따를 때 누적분포함수를 보여준다.

무선 링크 에러가 각각의 분포함수를 바탕으로 동적으로 변할 때 3 가지 기법들(local, best average 및 local \& best average repair schemes)을 최적의 기법(optimal repair scheme) 과 비교해본 결과 직관적으로 알 수 있듯이 제안한 기법 (local \& best average repair scheme)은 전체적으로 좋은 경로에서 무선 링크 손실이 발생해도 지역적으로 다른 좋은 다중 경로를 찾아서 기회적으로 데이터를 전송하기 때문에 최적의 기법과 성능 차이가 제일 작다. 결과, 사물 인터넷 기반 기기간 통신 무선환경은 지역적으로 그리고 랜덤으로 링크단위 에러가 많이 발생하기 때문에 average값만 고려한 방식보다 local값을 고려한 기법이 중요성하다는 것을 알 수 있다.

\section{5. 결 론}

본 논문에서는 사물 인터넷 기반 기기간 통신 무선 환경 에서 IoT 디바이스의 경량화 자동 주소 설정을 포함한 IPv6 이웃 발견 기법 및 향상된 $\mathrm{RPL}$ 기반 경량화 라우팅 프로토 콜을 제안했다. 제어 메시지 전송 횟수 및 사이즈를 줄여서 경량화 라우팅 프로토콜들을 제안했던 기존 연구들과 달리 본 연구에서는 노드 식별 $\mathrm{IPv6} 6$ 주소, 이웃발견 과정 및 데이 터 전송을 위한 라우팅 경로에서 발생하는 총 제어 메시지 양을 줄이는 RPL기반 향상된 경량화 라우팅 프로토콜을 제 안했다.

추후 연구로는 제안한 기법이 다른 기법들에 비해서 전력 소모량, IPv6주소 및 메시지 오버헤드 등이 성능평가 결과 에서 각각 얼마나 효과를 반영하는지 비교하고 경량화 라우 팅 프로토콜의 완성도를 한층 더 높이는 것이다. 


\section{References}

[1] 장원규, 이성협, "국내외 사물인터넷 정책 및 시장동향과 주요 서비스 사례”, 동향과 전망: 방송 - 통신 - 전파 통권 제 64 호 2013. 07.

[2] 고정길, 홍상기, 이병복, 김내수, “스마트 디바이스와 사물인터 넷(IoT) 융합 기술 동향”, 전자통신동향분석 제 28 권 제 4 호 2013년 8월.

[3] G. Fodor, E. Dahlman, G. Mildh, S. Parkvall, N. Reider, G. Mikls, and Z. Turnyi, "Design aspects of network assisted device-to-device communications", IEEE Commun. Mag., Vol.50, No.3, pp.170-177, Mar., 2012.

[4] 최계원, 이현, 장성철, "기기 간 직접통신을 위한 모바일 어플리 케이션 및 서비스 디스커버리 프로토콜”, 한국통신학회논문지 (J-KICS) '13-10 Vol.38A, No.10.

[5] L. Lei, Z. Zhong, C. Lin, and X. Shen, "Operator controlled device-to-device communications in LTE-Advanced networks", IEEE Wireless Commun. Mag., Vol.19, No.3, pp.96-104, June, 2012.

[6] D. Camps-Mur, A. Garcia-Saavedra, and P. Serrano, "Device-to-device communications with Wi-Fi Direct: overview and experimentation”, IEEE Wireless Commun., Vol.20, No.3, pp.1-8, June, 2013.

[7] IEEE, Wireless LAN medium access control(MAC) and physical layer(PHY) specifications amendment 9: interworking with external networks, IEEE Std. 802.11u, 2011.

[8] IETF, "RPL: IPv6 Routing Protocol for Low-Power and Lossy Networks", RFC 6550, Mar., 2012.

[9] J.H. Lim et al., "A Closed-Loop Approach for Improving the Wellness of Low Income Elders at Home Using Game Consoles”, IEEE Communications Magazine, Vol.50, No.1, pp. 44-51, Jan., 2012.

[10] 전자신문, "삼성-퀄컴 글로벌 반도체 기업, 헬스케어 시장 주 도권 다툼 치열", 2012. 7. 4.

[11] DailyTech, "스마트폰과 무선 센서 네트워크를 사용한 지능형 주차 서비스", 2008. 7. 14.

[12] Wireless Sensor Network Blog, "Valarm offers an affordable remote sensor and monitoring solution for Android devices", 2013. 4. 13 .
[13] J. Ko et al., "Connecting Low-power and Lossy Networks to the Internet", IEEE Communications Magazine, Vol.49, No.4, Apr., pp.96-101, 2011.

[14] IETF, "Transmission of IPv6 Packets over IEEE 802.15.4 Networks”, RFC 4944, Sep., 2007.

[15] J. Ko et al., "Wireless Sensor Networks for Healthcare", Proc. IEEE, Vol.98, No.11, pp.1947-1960, Nov., 2010.

[16] Z. Shelbyet al., "Constrained Application Portocol(CoAP)", IETF CoRE Working Group, Internet-Draft, Ver.18, June, 2013.

[17] Kunjan Patel, Lim Jong Chern, C.J. Bleakley, and Wim Vanderbauwhede, "MAW: A Reliable Lightweight MultiHop Wireless Sensor Network Routing Protocol”, 2009 International Conference on Computational Science and Engineering.

[18] Zehua Wang, Yuanzhu Chen, and Cheng Li, "PSR: A Lightweight ProactiveAd Hoc Networks", Vehicular Technology, IEEE Transactions Source Routing Protocol For Mobile on (Vol.63, Issue.2)

[19] Hu Shen, Xiaodong Wang, Yanqiang Sun, Yanrong Ding, and Xingming Zhou, "LALO: A Link-Aware Lightweight Routing Protocol for Data Delivery in Vehicular Ad Hoc Networks", Ubiquitous Intelligence and Computing Lecture Notes in Computer Science Vol.6406, pp.459-473, 2010.

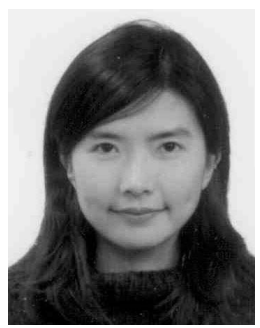

\section{오 하 영}

e-mail : hyoh@ssu.ac.kr 1998년 2002년 덕성여자대학교 2001년 2004년 신한금융지주회사 $\mathrm{e}^{-}$신한 2004년 2006년 이화여자대학교 컴퓨터공학 (석사)

2006년 2013년 서울대학교 컴퓨터공학(박사) 2010년 U.C. Berkeley 방문연구원

2013년 서울시립대학교 연구교수

2013년 현 재 숭실대학교 정보통신전자공학부 조교수 관심분야: 소셜 정보망, 추천시스템, 무선 네트워크 및 비디오 스트리밍 